\title{
Retention basin with Golesti SHPP downstream dam for mitigating hydropeaking and producing green electricity
}

\author{
Bogdan Popa ${ }^{1,{ }^{*},}$ Florica Popa $^{2}$, Eliza Isabela Tică ${ }^{1}$, Angela Neagoe $^{1}$, and Mihaela Amalia Diminescu ${ }^{1}$ \\ ${ }^{1}$ University Politehnica of Bucharest, 313 Spl. Independentei, 060042, Bucharest, Romania \\ ${ }^{2}$ University Valahia of Targoviste, 13 Aleea Sinaia, 130004, Targoviste, Romania
}

\begin{abstract}
Hydropeaking is due to the intermittent operation of peak hydropower plants and leads to various and complex problems downstream. A solution to solve part of them is to provide the development scheme with a retention basin downstream the hydropower plant (HPP). The water used intermittently during the day / week to produce electricity at peak load, which leads to sudden variation of flows into the riverbed will be regulated in this reservoir. Irrespective of the program that the HPP has during the day, the retention basin gathers the water and evacuates it downstream as much as possible constantly during the day or, at least, attenuates the sudden variation, increase or decrease, of levels downstream. Thus, the maximum flows evacuated by the HPP can be dramatically reduced as well as the flow fluctuations and the river levels accordingly. If the flow downstream the retention basin is almost constant during the day and it is released through a small hydropower plant, the positive effect of this reservoir on hydropeaking is combined with the production of green electricity. The subject of this paper is to roughly analyse the possibility to build a retention basin downstream Golesti HPP by means of weir and contour dams, if the case may be, and to release the water constantly or with smooth fluctuations, via one or two turbines, a small hydropower plant, producing green electricity without further harming the riverbed and the ecosystem downstream the weir.
\end{abstract}

\section{Introduction}

Reservoirs are the most important part of hydropower developments achieving the modification of longitudinal profiles of water courses and the alteration of water flow regimes [1]. Either of these two goals prevails depending on the hydropower development type and the role of the reservoir.

In what concerns the modification of water flow regimes, reservoirs can be classified as: regulation reservoirs (built on the main stream) and secondary regulation reservoirs sometimes named compensation or compensation and regulation reservoirs or, as referred in this paper, retention reservoirs or basins.

An extensive study regarding the impact of dams on river basins from the perspective of the disequilibrium created on all natural levels: morphology, ecology, hydrology both downstream and upstream, is seen in [2].

One of the major issues pointed out in relation to the storage hydropower plants is the intermittent functioning or hydropeaking. It can be defined as the sudden increase and decrease of flows downstream hydropower plants (HPPs), and levels accordingly, due to the operation of such plants on energy and / or ancillary services demand.

Other definitions of hydropeaking include: artificial increase and decrease of discharge and corresponding water levels in rivers, characterized by steep rising and falling limbs of hydrographs based on the operation of storage hydropower plants to generate electricity on energy demand [3], extreme downstream fluctuations in discharge and water levels or intense unnatural discharge fluctuations in downstream river reaches [4], severe daily and sub-daily fluctuations in discharge and water levels [5], short-term artificial changes in the water flow on a body of water causing severe harm to indigenous flora and fauna as well as to their habitats [6].

Within a hydropower development, the goal of the regulation reservoirs is to supply water to the HPP and that of the retention basins is to regulate discharges evacuated from the hydropower plant so as to diminish, as much as possible, the downstream negative effects related to hydropeaking.

An excellent review on the various aspects of hydropeaking and on research and publications related to it is made in [3]. Among the impacts that hydropeaking has, ecological impacts are mentioned, such as: river thermal dynamics, sediment transport, habitat quality and distribution, riparian vegetation, and hydromorphological pressures. The authors mention that in order to deal with ecological impacts of hydropeaking in some European countries the legislation establishes 1:3 as limit of the ratio between the minimum flow and the maximum flow downstream a HPP. The greater the maximum flow than three times the minimum flow, the greater the negative impacts on aquatic ecology.

Hauer et. Al. [3] consider that the papers having as subject hydropeaking can be grouped into five topics: (i) improved process understanding and biotic response, (ii)

\footnotetext{
* Corresponding author: bogdan.popa@upb.ro
} 
advances in modelling tools and extended methods in hydropeaking analysis, (iii) new conceptual approaches for hydropeaking management, (iv) mitigation measure design and practical experience, and (v) socioenvironmental interactions related to hydropeaking.

From among these five topics, the present paper address issues related to the third and fourth, i.e. new conceptual approaches for hydropeaking management and mitigation measure design and practical experience.

Other authors present a set of indicators that can be predicted and that cover all phases of hydropeaking from hydrological to the most importantly affected biotic and abiotic processes [4]. The resulted framework allows a comparison of the effects of hydropeaking among different mitigation measures, to the previous situation and to the reference situation.

Regarding the hydrological regime, rapid variations of flow and water level can exceed by far those of the natural regime several times over a day. The distinct hydrological phases of hydropeaking are: low flows when the HPP is stopped, rapid increase or decrease of flow when the HPP starts or it stops, high flow when the HPP produces electricity at the maximum load.

The case presented in [5] is that of a HPP already producing hydropeaking where the owner intends to increase the installed capacity and implement mitigation measures for hydropeaking. The authors defined three scenarios: current state, upgraded HPP, and upgraded HPP with mitigation measures for hydropeaking.

In analysis, the authors used 12 ecological indicators: Fish community structure (F1), Fish stranding (F2), Fish spawning grounds (F3), Fish reproduction (F4), Fish productivity (F5), Macroinvertebrate biomass (M1), Macroinvertebrate diversity (M2), Longitudinal zonation of macroinvertebrates (M3), Diversity of sensitive macroinvertebrate taxa (M4), Substrate clogging (S1), Minimal discharge (D1) and Water temperature (T1).

In addition to the increased interest in research and management, the legislative framework has been adapted lately so as to deal with hydropeaking: water framework directive (WFD) at European Union (EU) level and, as an example at national level, Swiss Water Protection Act (WPA) [6]. WPA is an example of Swiss precision. It is stipulated that those in charge of a certain hydropower development, if it is the case, are obliged, to prevent or to eliminate within 20 years of this provision coming into force, by means of civil engineering measures short-term artificial changes in the water flow on a body of water (hydropeaking) that cause severe harm to the indigenous flora and fauna as well as to their habitats. At the request of the person responsible for a hydropower plant, the authority may order operational instead of civil engineering measures.

The measures are determined by: the degree of harm caused to the body of water; the ecological potential of the body of water; the proportionality of the cost; the interests of flood protection; the energy policy goals relating to the promotion of renewable energy sources.

The low rate of increasing and decreasing the flow when starting a unit can be emphasised among the operational measures.
As a result of WPA, [6], a legal basis was created to enforce the reduction of adverse ecological impacts from hydropeaking to be achieved by means of appropriate structural or operational mitigation measures by 2030 .

As an example to be followed, in Switzerland, mitigation of hydropeaking is divided into four main phases: identification of the HPP causing hydropeaking (4 years), establishment of the most appropriate mitigation measure, implementation by owners of the best mitigation measures for which they receive financial support (from a fund fed by an electricity consumption surcharge of 0.1 cent $/ \mathrm{kWh}$ ), and verification of measures effectiveness (comparison with previous situation).

Trying to answer the question of sustainable hydropower reservoir operation, some authors identified optimization problems with 3 different environmental goals: to provide flows needed for fish habitat, to mimic the natural flow regime and to provide flow regimes to support a healthy fish population [7]. Speaking about the second from the above enumerated goals, if a reservoir has in place for more than 20 years and downstream the river bed has been affected by hydropeaking, is it enough to recreate the natural variation in flow following the philosophy that healthy river ecosystems need a natural range of variation in flow? This approach addresses an important failing of the habitat-based approach: the fact that maintaining the diversity of slack water and channelized habitats with a suitable composition of substrates requires occasional channel-shaping flows, rather than simply a constant 'optimal' flow or nonoptimal minimum flow.

Other studies were done having as goal: different approaches to characterize the sub daily flow regimes, so to deal with hydropeaking $[8,9]$; the influence of hydropeaking on invertebrates [10] or, in general, on aquatic fauna [11] or on the riverine plants [12] or simultaneously on the ecological and hydrological conditions [13]. Focused on the hydrological influence of hydropeaking, other researchers draw attention to the fact that among its effects are: significant shortening of spring floods, reduction of the duration and depth/intensity? of summer droughts, decrease of the maximum discharge, and homogenization of the discharge hydrographs [14].

Other authors [15] realized a hydrodynamic model to simulate the link between hydropeaking and the thermal pollution of the river downstream the HPP, but also into the reservoir itself (vertical mixing of layers). Their conclusion was that these effects can be avoided simply by introducing in the operation of coupled reservoir HPP systems some constraints that they name environmental constraints (EC). The economic costs for the case study are just $0.3 \%$ of the total operational costs.

Some authors [16] consider local river widening as a potential rehabilitation tool as a structural measure to deal with hydropeaking focusing on its effects in relation to the longitudinal and vertical dimensions. The need for measures on hydropeaking mitigation is shown in a graph demonstrating a common regime due to HPP in the water level of the river Rhone, where during weekdays there are variations up to $1.5 \mathrm{~m}$ and during weekends the level is almost constant. They mention as 
methods for the attenuation of hydropeaking: retention basins (as a structural measure) or slower up and down ramping of turbines (as an operational measure) and consider that local river widening, an engineering measure for preventing incision, has a significant morphological and hydraulic potential. Among their conclusions, the following should be mentioned: the winter warming and summer cooling of the river water, and the fact that soft methods (operational) are effective only in combination with hard methods (storing the water in retention basins or underground reservoirs before being continuously discharged into the river). Perhaps the most important conclusion is that adaptation of hydropower development from the ecological point of view requires an integrated approach and is considerable as financial effort, but, however, it is more appropriate than subsidizing other more expensive sources of electricity.

An earlier socio-economic evaluation showed that retention volumes (i.e. basins and caverns) were the only structural measures that could mitigate hydropeaking impacts with a realistic cost-to-benefit ratio [17]. For instance, direct diversion of turbined water into Lake Brienz was excluded due to extensive cost. Furthermore, operational measures directly at the hydropower plant (e.g. a decrease in peak flow, or a reduction in ramping and falling rates) were also discarded a priori because in Switzerland they can only be imposed by the relevant authority if chosen by the hydropower owner over structural measures. This reflects a political decision taken during the revision of the WPA, which aims at minimizing the negative consequences of operational measures, such as reduced flexibility of production and lowered supply of renewable energies.

Due to this observation, as with different mitigation measures, the authors used only the realisation of a basin having four different volumes: a: $50,000 \mathrm{~m}^{3}$; b: 60,000 $\mathrm{m}^{3}$; c: $80,000 \mathrm{~m}^{3}$; $\mathrm{d}: 100,000 \mathrm{~m}^{3}$.

The choice was the compensation basin with the volume of $80,000 \mathrm{~m}^{3}$. The smallest basins were rejected because they did not comply with the legal obligation to sufficiently mitigate the severe harm to aquatic organisms and their habitat caused by hydropeaking and the largest one has too high costs as compared with the chosen one.

Regarding how far from the HPP hydropeaking must be taken into account, [18] presents a complex study on the variation of vertical ramping velocity with the distance from turbine outlet. Moreover their assessments were made taking into account that turbine shut-down from peak flow to base flow is done within $1,2,5,15$, 30,60 and $120 \mathrm{~min}$. One of the main conclusions of this study is that on the first $5 \mathrm{~km}$ downstream the evacuation of the water from turbines a dramatic decrease in vertical ramping velocity occurs, so this is the most important sector to address in hydropeaking issues. Obviously, with the increase of the turbine shut-down time the vertical ramping velocity dramatically decreases.

The same issue of a retention basin considering the extension of an existing complex HPD is subject of many studies [19-22]. The importance of the realisation of the needed volume of the retention basin needs to be emphasised in order to mitigate hydropeaking issues. Since the needed volume could not be obtained only by means of a surface basin (maximum storage capacity is $20,000 \mathrm{~m}^{3}$ ), a new tailrace tunnel was built (representing also an underground storage gallery), with cross section and length sufficient to ensure $60,000 \mathrm{~m}^{3}$ in conditions of free surface flow, ensuring the needed volume of $80,000 \mathrm{~m}^{3}$.

In [22] the authors evaluate the future performance of such a basin for the planned addition of another reservoir to an existing hydro system, built for the purpose of reducing the up and down surge rates without limiting the ratio between the base flow and the peak flow. Aare River at Innerkirchen is the case study, hydropeaking corresponding to a variation of discharges between 3 and $53 \mathrm{~m}^{3} / \mathrm{s}$. The construction of a retention basin with a volume of $80,000 \mathrm{~m}^{3}$ has been identified as a cost effective measure to remediate hydropeaking. Regarding hydropeaking regulations, a global limit of \pm 2.5 $\mathrm{m}^{3} / \mathrm{s} / \mathrm{min}$ was imposed for the rate at which the water level increases or recedes, defined in the license regulating the exploitation rights. For analysis the authors used three scenarios considered not to provide an accurate depiction of the future operation but to cover a certain range of potential operation patterns: demand, demand - peak and demand - smooth. Underlining that the operation of a storage reservoir is a Markov decision process: at each time step a decision is taken according with the minimisation or maximisation of an objective function based on incomplete data regarding future behaviour of the system and depending on the present state of the system, the authors conceived a rolling horizon optimisation model. The model is run for a time horizon of 30 and 45 minutes with the hypothesis that it can be implemented in reality. The overall conclusion of their study was that under all assessed future operation scenarios the basin is able to attenuate hydropeaking respecting the agreed thresholds. Such a model is also suitable for dimensioning the retention basin.

A recent and complex paper [23] refers to 5 storage HPPs on Valsura River, where the concession agreement demands the investigation of hydropeaking problems and the elaboration of related measures for mitigation downstream the last HPP, Lana. The hydraulic simulations were done using BASEMENT software and, based on the obtained results a habitat simulation with CASiMiR software was performed. Graphs showing the steep variation from 2 to $26 \mathrm{~m}^{3} / \mathrm{s}$ and backward, in single peak or double peak production profile, in the riverbed downstream Lana HPP prove the heavy hydropeaking morphological and ecological pressure. Moreover, the peak energy production must be considered balanced with the irrigation supply as the other important water use of Alborelo multipurpose reservoir. The authors compare operational and constructive hydropeaking mitigation measures and demonstrate that, in this case, constructive measures can lead to positive effects from the ecological and safety standards points of view, at the same time having some negative effects on peak energy production. The measures combine change in operation of Alborelo reservoir with the construction of a multipurpose compensation basin downstream Lana 
HPP, from which part of the water goes to supplement irrigations and part to a new HPP, Lana di Sotto. The active volume of Alborelo reservoir is $2,400 \cdot 10^{3} \mathrm{~m}^{3}$, and supplies water both for irrigation and for Lana HPP which has a maximum discharge of $26.25 \mathrm{~m}^{3} / \mathrm{s}$. The active volume of the compensation reservoir for Lana HPP discharges is $95 \cdot 10^{3} \mathrm{~m}^{3}$, and supplies water both for irrigation and for the new Lana di Sotto HPP, which has a maximum discharge of $13 \mathrm{~m}^{3} / \mathrm{s}$. A simple calculation leads to a ratio of volumes of 25 and of discharges of 1.6. The operational measures for Alborelo reservoir lead to a decrease from $60 \%$ to $40 \%$ of the flow used for peak energy correlated with an increase of the same magnitude, $20 \%$, for off-peak energy flow, from $28 \%$ to $48 \%$, the reserve flow remaining constant as well as the irrigation flow surge tank, $11 \%$ and $1 \%$ respectively. The maximum flow will be dramatically reduced, from 26.25 to $9.4 \mathrm{~m}^{3} / \mathrm{s}$. The new compensation basin uses $88 \%$ for peak energy flow and the same percentages for reserve flow and irrigation.

Therefore a solution to the problem of hydropeaking is to provide the development scheme with a retention basin downstream the hydropower plant. The water used intermittently during the day / week to produce electricity at peak load will be regulated in this reservoir. Irrespective of the program the HPP has during the day, the retention basin accumulates water downstream and evacuates it as constantly as possible during the day. Thus, the maximum flows evacuated by the HPP can be dramatically reduced as well as the flow fluctuations and the river levels.

If the flow downstream the retention basin is close to constant or the sudden fluctuations are smoothed during the day and it is released through a small hydropower plant, the positive effect of this reservoir on hydropeaking is combined with the production of green electricity.

The subject of this paper is to roughly analyse the possibility to build downstream Golesti HPP a retention basin by means of a weir and contour dams, if the case may be, and to release the water constantly, without fluctuations, or, at least, to smooth the sudden variations of flows in the riverbed, through one or two turbines (a SHPP) producing green electricity without further harming the riverbed and the ecosystem downstream the weir. Operational measures will not be taken into account as they are very expensive for the operator and affect one of the most important goals of a HPP, namely the quick start and stop of turbines. Also, for implementing operational measures, increasing time for start and shut down means an increase of water volumes used without producing electricity, which can be considered lost from this point of view. Certain compensation measures can be envisaged.

\section{Retention reservoirs in Romania}

River hydropower developments (HPDs) in Romania have a large reservoir for the main regulation of river flows which supplies water for a large HPP, named cascade head HPP. The second reservoir of the river has as main goal the retention of the water used by the cascade head HPP. These cases are presented below:

1. HPD Somesul Mic, Fantanele reservoir, cascade head, downstream Tarnita reservoir followed Floresti II retention reservoir which evacuates in Somesul Mic River;

2. HPD Raul Mare Retezat, Gura Apelor reservoir, cascade head, downstream Ostrovul Mic retention reservoir;

3. HPD Bistra Poiana Marului - Ruieni - Poiana Rusca, Poiana Marului, reservoir, downstream Zervesti retention reservoir which evacuates in Bistra Marului River;

4. HPD Cerna - Motru - Tismana, Cerna reservoir, cascade head, downstream Valea Mare reservoir, downstream Tismana retention reservoir which evacuates in Tismana River;

5. HPD Jiu, Valea Sadului reservoir in execution, cascade head, downstream $\mathrm{Tg}$. Jiu retention reservoir which evacuates in Jiu River;

6. HPD Olt superior, Venetia reservoir in execution, cascade head, downstream Voila retention reservoir;

7. HPD Lotru, Vidra reservoir, cascade head, downstream Malaia retention reservoir;

8. HPD Arges, Vidraru reservoir, cascade head, downstream Oiesti retention reservoir;

9. HPD Raul Targului, Rausor reservoir, cascade head, downstream Leresti retention reservoir;

10. HPD Dambovita, Pecineagu reservoir, cascade head, downstream Satic retention reservoir;

11. HPD Upstream Buzau, Ciresu reservoir in execution, cascade head, downstream Nehoiasu retention reservoir.

12. HPD Bistrita, Izvorul Muntelui reservoir, cascade head, downstream Pangarati retention reservoir.

It should be stated that the reservoirs mentioned as regulation reservoirs have this role for the upstream reservoir this being, in most of the cases, only one of the reservoirs roles.

\section{Golesti hydropower development, case study for hydropeaking}

A short description of Golesti HPD is presented in [24]. It is part of the development of Argeș river which has one of the most important catchments in Romania. River Argeș has $340 \mathrm{~km}$ in length and its catchment area is of $12,550 \mathrm{~km}^{2}$. Golesti is the sixteenth HPD on the upper Arges river development with a dam type HPP reservoir, having the gross storage of $44.9 \mathrm{mil} . \mathrm{m}^{3}$ corresponding to a normal retention level at 253 MASL; the downstream level is 241 MASL. The dam occupies the minor riverbed of Arges river, which is a meandering course with the width varying between 50 and $100 \mathrm{~m}$. The major riverbed is unevenly developed and the average width is $300 \mathrm{~m}$.

The front dam is $450 \mathrm{~m}$ long and $22 \mathrm{~m}$ high (thalweg altitude is 236.5 MASL) and it incorporates a HPP and a pumping station, figure 1 . The servitude flow of $1.8 \mathrm{~m}^{3} / \mathrm{s}$ is provided through 2 pipelines in the penultimate spans of the high water discharger. Downstream is the $34 \mathrm{~m}$ 
dissipater, a settlement basin $25 \mathrm{~m}$ length, a risberma at 235.5 MASL, on a length of $30 \mathrm{~m}$ and width of $155 \mathrm{~m}$, continued with a trapezoidal embankment to a width of $232 \mathrm{~m}$ on a length of $48 \mathrm{~m}$.

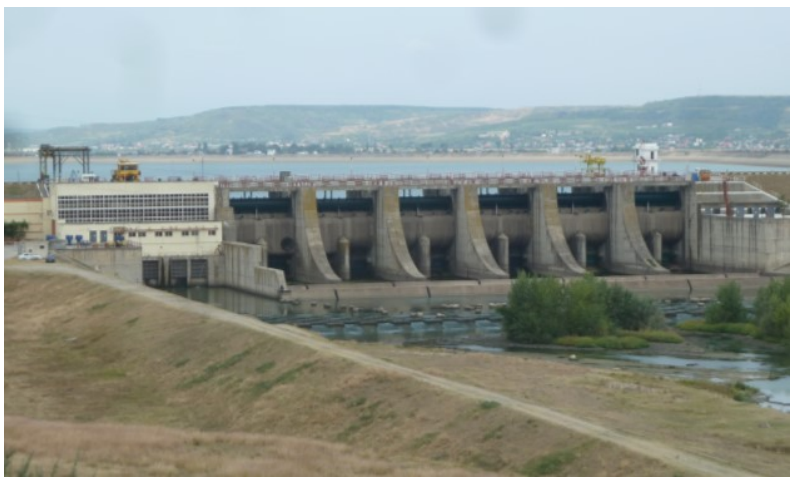

Fig. 1. Golesti HPD, downstream view (Photo B. Popa).

Golesti reservoir has multipurpose use: water supply for Bucharest (mean flow $1.8 \mathrm{~m}^{3} / \mathrm{s}$ ), reserve water supply for ARPECHIM Pitesti (maximum flow $6 \mathrm{~m}^{3} / \mathrm{s}$, mean flow $0.77 \mathrm{~m}^{3} / \mathrm{s}$ ), irrigation for Cateasca-Teiu system for 10,000 ha (installed flow $9 \mathrm{~m}^{3} / \mathrm{s}$, authorised mean flow $2.98 \mathrm{~m}^{3} / \mathrm{s}$ for 120 days/year), water supply for Golesti HPP (gross head $16 \mathrm{~m}$, installed flow $90 \mathrm{~m}^{3} / \mathrm{s}$, installed capacity $8 \mathrm{MW}$ in 2 Kaplan turbines), storage reserve for floods attenuation $\left(12 \mathrm{mil.} \mathrm{m}^{3}\right)$.

Golesti HPP operation is made in the following way: one turbine runs continuously and the second one goes into operation only if needed, on average one third of the time. This can be deduced from the flow duration curve (FDC) of daily flows used in HPP Golesti for 11 years, 2006-2016, figure 2.

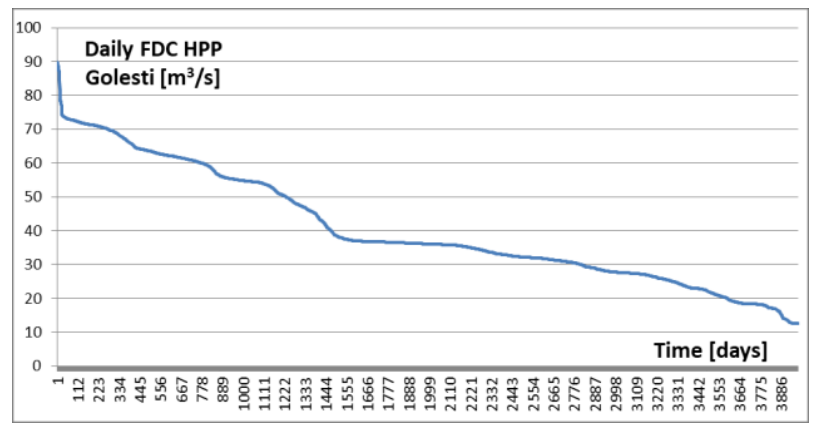

Fig. 2. Flow duration curve (FDC) of daily flows used in HPP Golesti for 11 years, 2006-2016.

From the data for daily flows used by Golesti HPP for 11 years, 2006-2016, daily flows for each month of a normal hydrological year were represented on the same graph, figure 3.

The first conclusion is that there are no significant differences between weekdays and weekends regarding the electricity production. Golesti is not a peak HPP but a HPP functioning on demand. From graphs one can notice that most of the daily step variations are around $35 \mathrm{~m}^{3} / \mathrm{s}$, with a minimum of $18 \mathrm{~m}^{3} / \mathrm{s}$, which means HPP in operation with one turbine, and the other operating level is around $70 \mathrm{~m}^{3} / \mathrm{s}$, with a maximum of $95 \mathrm{~m}^{3} / \mathrm{s}$, i.e. HPP in operation with two turbines. This suggests that
Golesti HPP could generate problems downstream due to sudden variations of flows.

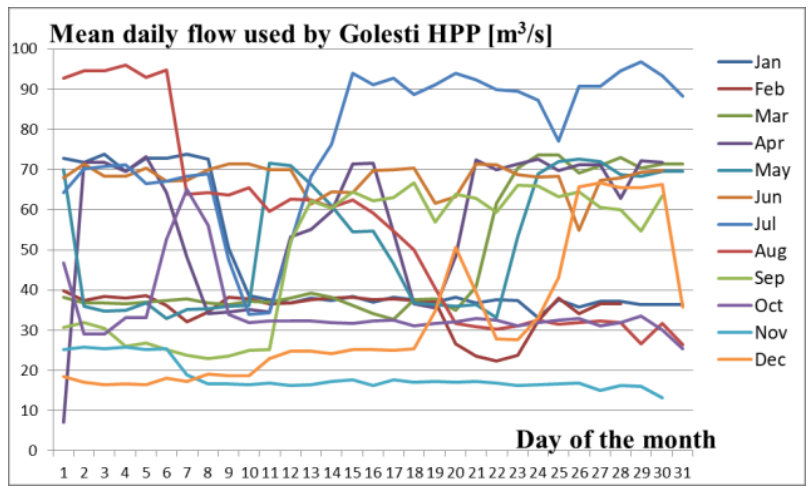

Fig. 3. Daily flows used by Golesti HPP in a normal year.

Photos covering the first $1300 \mathrm{~m}$ downstream Golesti dam, taken from the right bank, are presented in figures 4 to 7 .

Due to the intermittent operation of Golesti HPP, the riverbed downstream is affected, as well as the ecosystem. Correlated with the aspect of the riverbed downstream the dam, Golesti HPD was chosen as case study for demonstration of hydropeaking and related mitigation measures.

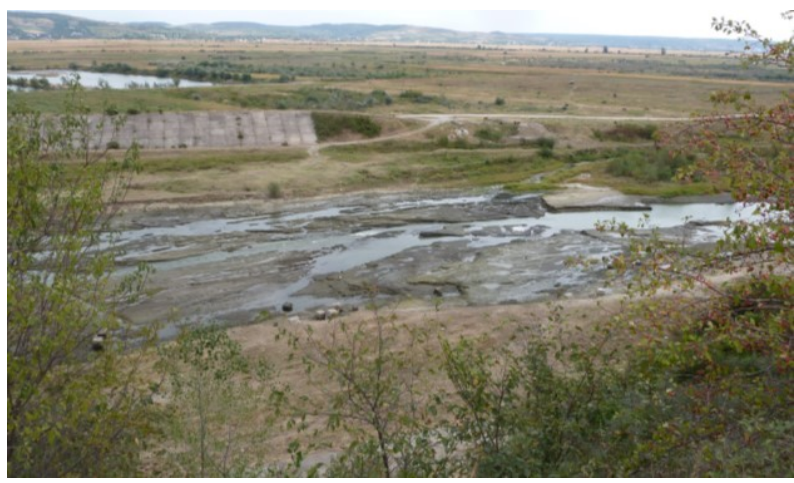

Fig. 4. Arges river downstream Golesti HPP (Photo B. Popa).

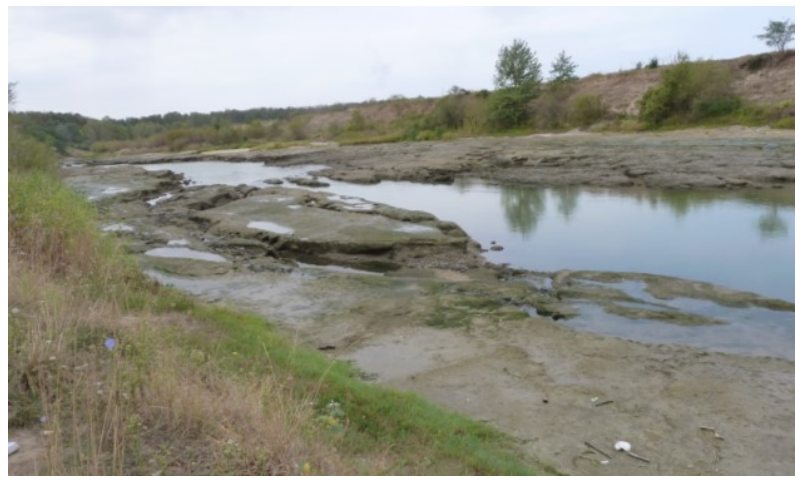

Fig. 5. Arges river downstream Golesti HPP (Photo B. Popa).

More than that, along tens of kilometres downstream Golesti there is no other reservoir, hence it could be beneficial to realize a retention basin to create a small head and to regulate flows from Golesti when the second turbine starts or stops. The head allows the use of hydraulic energy to produce electricity with the help of one low head turbine and a flap gate or the second 
turbine can be used when the second turbine from Golesti starts so as to mitigate the hydropeaking effects.

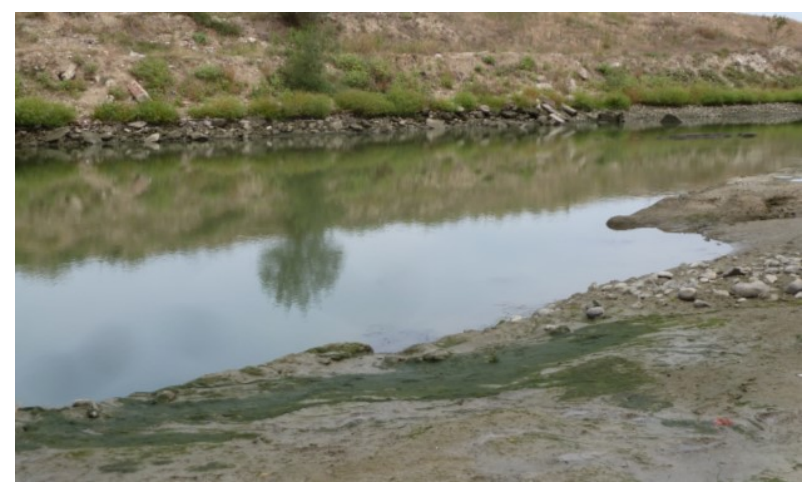

Fig. 6. Arges river downstream Golesti HPP (Photo B. Popa).

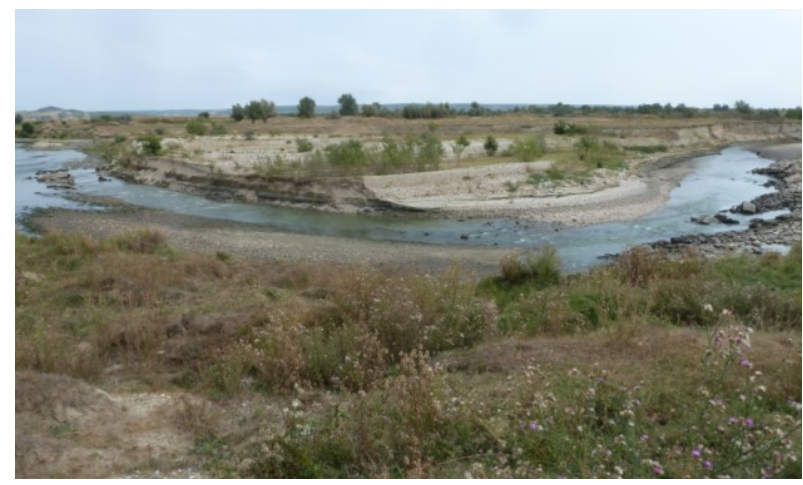

Fig. 7. Arges river downstream Golesti HPP (Photo B. Popa).

We may consider that the goal of the retention reservoir is to realise a small head of water and to transform the sudden increase or decrease of flow downstream, due to start or stop of the second turbine, into smoothed variations, e.g. to have downstream the weir the flow evacuated by Golesti after one hour. In this case, the live storage is the product of the mean flow of the second turbine, $35 \mathrm{~m}^{3} / \mathrm{s}$, and the time, one hour, in seconds. A live storage of: $126,000 \mathrm{~m}^{3}$ results.

It must be noticed that when Golesti HPP runs with only one turbine, the goal of the weir is to create a head so that the water flowing through a low head turbine should produce green electricity, otherwise the hydraulic energy causes riverbed erosion. The total volume of the retention reservoir is the sum of the storage corresponding to the designed head of the turbine and the storage needed to deal with hydropeaking.

One of the turbines which are capable to use low heads is the Very Low Head (VLH) turbine, figure 8. The typical range of heads of VLH is from 1.5 to $4.5 \mathrm{~m}$ and the range of flow rates extends from 10 to $27 \mathrm{~m}^{3} / \mathrm{s}$.

Having in mind that Golesti HPP runs most of the time at $35 \mathrm{~m}^{3} / \mathrm{s}$ and one third of the time at $70 \mathrm{~m}^{3} / \mathrm{s}$, the equipping of the weir of the retention reservoir can be with one or two VLH turbines. The role of the second turbine can be taken over by flap gates.

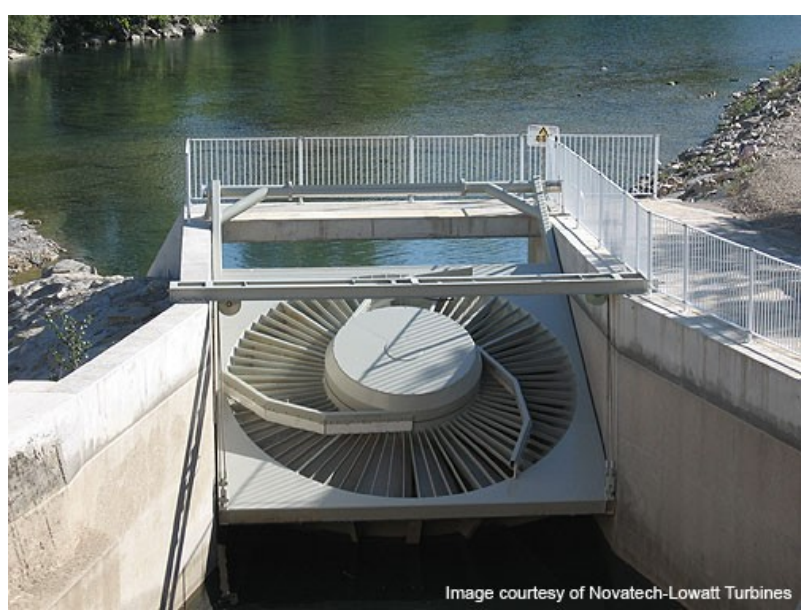

Fig. 8. Very Low Head (VLH) turbine (https://www.powertechnology.com/features/feature115301/).

\section{Retention basin downstream Golești HPD}

To perform a GIS-based analysis of the sector of Golesti HPD the Digital Elevation Model (DEM) of the area must be processed, which can be freely downloaded from Websites as: USGS Earth Explorer [25], NASA Earth Data [26] or Open Topography [27]. For this study, the DEM obtained from the USGS Earth Explorer website was used, figure 9.

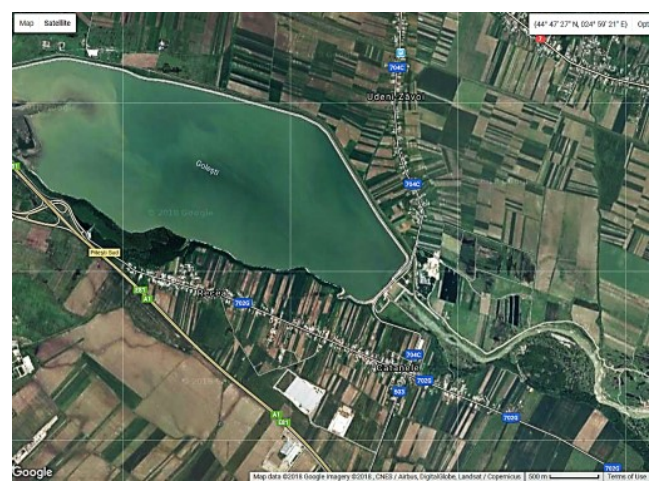

Fig. 9. Golesti HPD and downstream (Google maps view).

After selection of the analysed area, the types of files desired to be downloaded will be checked. In this case, it SRTM 1 Arc-Second Digital Terrain Elevation Global was selected, the files having the extension.GeoTIFF. In figure 10 are presented the 2 rectangles that include the study area, and for the location of Golesti reservoir a polygon was drawn over it.

This metadata format provides geographic information which is associated with the image data, and their processing was done by open source software [28] and HEC-RAS 5.0.5 [29].

At the beginning the two GeoTiff files were merged in order to work more easily. Even if every pixel of the GeoTiff images has an associated value for the elevation, the projection of this file is WGS 84 and for further processing it must be in UTM $35 \mathrm{~N}$. 


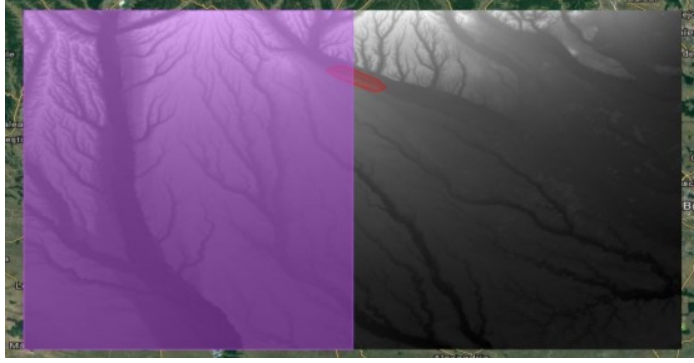

Fig. 10. DEM of the sector of Golesti HPD and the riverbed downstream the dam transformed in QGIS (ASTER GDEM is a product of METI and NASA).

After changing projection of TIFF image files, a Clip Raster for the area of interest was extracted, which is presented in figure 11. The same figure illustrates the isohypses extracted from DEM and the Triangular Irregular Networks (TIN) on which the cross sections are extracted.

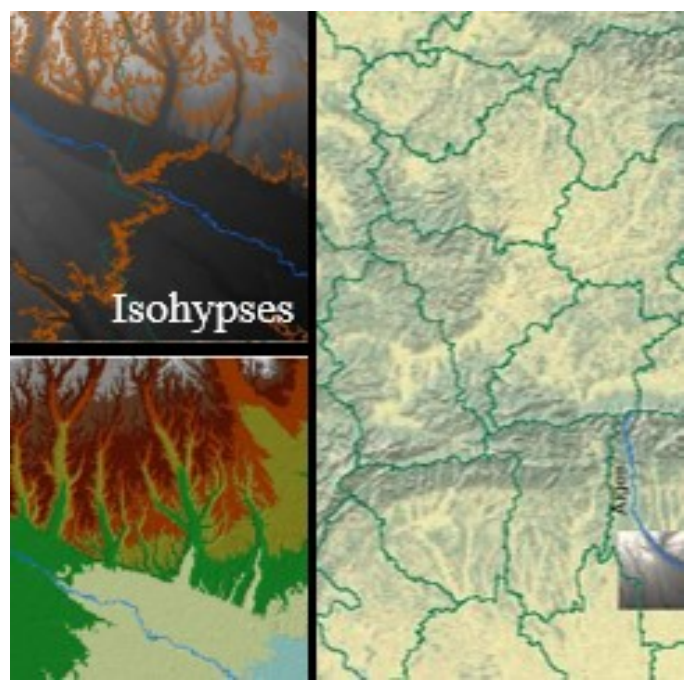

Fig. 11. Clip Raster, isohypses and TIN surface for study area.

The upstream condition for the retention reservoir is that the free surface level is not greater than the level of the risberma, so that it does not influence the head of Golesti HPP. The downstream limit is chosen so as to realize a head greater than $1.5 \mathrm{~m}$ and a volume between this level and the maximum level around $126,000 \mathrm{~m}^{3}$.

If the downstream limit is chosen like in figure 12 and the normal retention level of the retention reservoir is set up to the level of the risberma the volume of the reservoir results $313,000 \mathrm{~m}^{3}$, large enough to realize the needed head for the turbine and the smoothing of flow variations downstream.

The weir must be with a sill (floor bed) with the crest level around the level of the actual thalweg and flap gates to avoid obstruction of the cross section and to allow the transit of large discharges. The goal of the retention basin is to regulate the discharge used by Golesti HPP, and not to attenuate floods. This is one of the goals of Golesti reservoir.

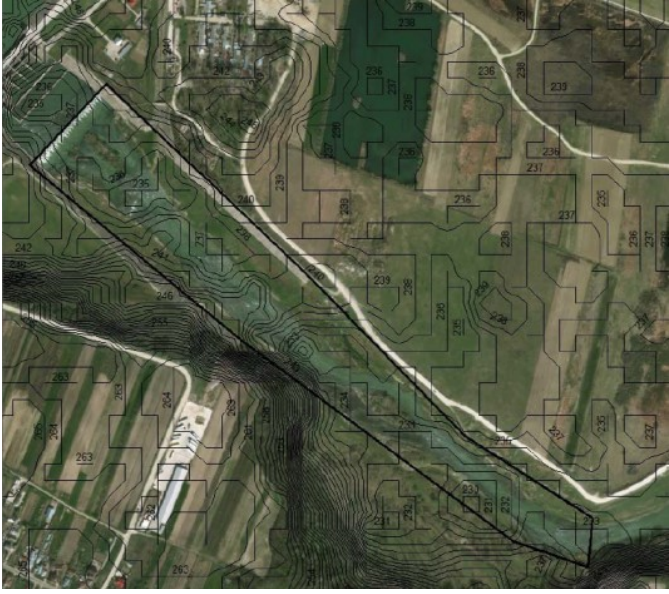

Fig. 12. Cross section lines downstream Golesti dam.

\section{Conclusions}

Romania has great experience in hydropower engineering with almost $7 \mathrm{GW}$ installed in more than 100 large HPPs and 600 SHPPs (according to the EU definition adopted in national legislation, HPPs having the installed capacity of at most $10 \mathrm{MW}$ ). Nevertheless, there are incomplete HPDs, i.e. with no retention reservoir downstream a significant peak HPP which causes riverbed destruction as a result of the undesired hydropeaking phenomenon.

The paper presented a qualitative analysis of the possibility to build a retention reservoir downstream Golesti HPP by means of a weir and contour dams, if the case may be, and to release the water without or with smoothed fluctuations, through a SHPP producing green electricity, without further harming the riverbed and the ecosystem downstream the weir. The paper addressed only the issue of this structural measure without taking into account operational measures at Golesti HPP which are very expensive for the operator and affect the quick start and stop of turbines. This is one of main positive features of HPPs and increasing the time for start and shut down turbines implies loss of water volumes. Also no ecological or hydrological issues were addressed.

Considering the complexity of the subject, the discussion is at the beginning. If the national legislation does not stipulat that this kind of measures must be taken in order to diminish hydropeaking, it is hard to believe that someone will invest in such a retention reservoir in Romania. The more so as water used in order to produce electricity in the SHPP attached to the weir must be paid, the equivalent of $1.1 \mathrm{Euro} / 1000 \mathrm{~m}^{3}$, which makes such an approach not economically viable for low head, which is the case. If changes occur and, under certain installed capacity SHPPs become exempt from paying this water tax, a private investor could be interested in participating in the construction of such an objective. All the more so as this SHPP might be the first of a cascade. Once downstream this SHPP the flow is almost constant it is easy to envisage a cascade of low head SHPPs, provided that legislation is adapted in order to encourage the use of this low head hydropower potential. 
It is useless to oblige dams and weirs owners to build fish passes in their constructions without having studies related to fish flora and fauna and without having in mind the adaptation of the HPP operation, related to hydropeaking and river restauration downstream.

This work has been funded by University Politehnica of Bucharest, through the "Excellence Research Grants" Program, Ctr. No. 8/25.09.2017 (SI - Acvi), UPB-GEX 2017.

The authors thank Hidroelectrica SA, the company who owns and operates Golești HPP and ISPH Project Development SA for their support regarding hydrological and operational data.

\section{References}

1. V. Chiriac, A. Filotti, I. Teodorescu, Reservoirs (in Romanian CERES Publishing House, Bucharest, 1976)

2. S. Schmutz, O. Moog, Riverine Ecosystem Management, 111-127. (Springer, Cham, 2018) https://link.springer.com/book/10.1007/978-3-31973250-3

3. C. Hauer, A. Siviglia, G. Zolezzi, Sci Total Environ, 579, 22-26 (2017) https://doi.org/10.1016/j.scitotenv.2016.11.028

4. A. Bruder, D. Tonolla, S. Schweizer, S. Vollenweider, S.D. Langhans, A. Wüest, Sci Total Environ, 568, 1204-1212 (2016) https://doi.org/10.1016/j.scitotenv.2016.05.032

5. D. Tonolla, A. Bruder, S. Schweizer, Sci Total Environ, 574, 594-604 (2017) https://doi.org/ 10.1016/j.scitotenv.2016.09.101

6. WPA.2011, Federal Act on the Protection of Waters (Waters Protection Act, WPA) (2016) https://www.admin.ch/opc/en/classifiedcompilation/19910022/201601010000/814.20.pdf

7. Henriette I. Jager, B.T. Smith, River. Res. Applic., 24, 340-352 (2008) https://doi.org/10.1002/rra.1069

8. C. Alonso, A. Roman, M.D. Bejarano, D.G. de Jalon, M. Carolli, Sci Total Environ, 574, 532-543 (2017) https://doi.org/10.1016/j.scitotenv.2016.09.087

9. M.D. Bejarano, A. Sordo-Ward, C. Alonso, C. Nilsson, J. of Hydrol., 550, 186-200 (2017) https://doi.org/10.1016/j.jhydrol. 2017.04.023

10. M.C. Bruno, B. Maiolini, M. Carolli, L. Silveri, Int. J. Lim., 45, 157-170 (2009) https://doi.org/10.1051/limn/2009018

11. O. Moog, R. Riv.: Res. \& Man., 8, 5-14 (1993) https://doi.org/10.1002/rrr. 3450080105

12. M.D. Bejarano, R. Jansson, C. Nilsson, Biol. Rev., 93, 658-673 (2018) https://doi.org/10.1111/brv.12362

13. Q. Chen, X. Zhang, Y. Chen, Q. Li, L. Qiu, M. Liu, Ecol. Eng., 77, 40-50 (2015) https://doi.org/10.1016/j.ecoleng.2014.12.017

14. P. Marcinkowski, M. Grygoruk, Wat., 9, 783-802 (2017) https://doi.org/10.3390/w9100783
15. D. Carpentier, J. Haas, M. Olivares, A. de la Fuente, Wat., 9, 367-385 (2017) https://doi.org/10.3390/w9060367

16. M. Fette, C. Weber, A. Peter, B. Wehrli, Env. Mod. and Ass., 12, 257-267 (2007) https://doi.org/10.1007/s10666-006-9061-7

17. E. Person, M. Bieri, A. Peter, A.J. Schleiss, 7, 580 599 (2014) https://doi.org/ 10.1002/eco.1380

18. C. Hauer, P. Holzapfel, P. Leitner, W. Graf, Sci Total Environ, 575, 1503-1514 (2017) https://doi.org/10.1016/j.scitotenv.2016.10.031

19. M. Bieri, M. Müller, S. Schweizer, A.J. Schleiss, Proceedings of River Flow 2014, Special Session on Swiss Competences in River Engineering and Restoration, 181-190, (Schleiss, Speerli \& Pfammatter Eds, Taylor \& Francis Group, London, 2014) https://infoscience.epfl.ch/record/202039

20. M. Muller, M. Zahno, Y. Keller, P. Billeter, J. Stamm, M. Kost, HYDRO 2014, BUILDING ON RECENT DEVELOPMENT PROGRESS, Session 20: Hydro plant rehabilitation and refurbishment (2014)

https://www.engineering-

group.ch/fileadmin/documents/06 news und publik ationen/publikationen/02_Kraftwerksbau/powerstation-construction-building-new-power_plantsunder-exploitation-neighboring-hydropowerschemes-iub-enginereing-ltd-publication.pdf

21. M. Müller, Y. Keller, P.A. Billeter, R. Kaderli, M. Gehri, M. Kost (2016) https://pdfs.semanticscholar.org/9986/3818217fe128 1 fa0620c6f923e4a516e3d8e.pdf? ga=2.37011424.1 710453481.1538858887-689284995.1533958027

22. P. Meier, P. Manso, M. Bieri, A.J. Schleiss, S. Schweizer, A.U. Fankhauser, B. Schwegler (2016) https://pdfs.semanticscholar.org/9986/3818217fe128 $1 \mathrm{fa} 0620 \mathrm{c} 6 \mathrm{f} 923 \mathrm{e} 4 \mathrm{a} 516 \mathrm{e} 3 \mathrm{~d} 8 \mathrm{e} . \mathrm{pdf} ? \mathrm{ga}=2.197628015$. 1710453481.1538858887-689284995.1533958027

23. G. Premstaller, V. Cavedon, G.R. Pisaturo, S. Schweizer, V. Adami, M. Righetti, Sci Total Environ, 574, 642-653 (2017) https://doi.org/10.1016/j.scitotenv.2016.09.088

24. L.I. Vuță, B. Popa, G.E. Dumitran, E. Tica, F. Popa, International Multidisciplinary Scientific Geo Conference Surveying Geology and Mining Ecology Management, SGEM, $17 \quad$ (42), 83-90 (2017 https://sgemworld.at/sgemlib/spip.php?article9966

25. USGS Earth Explorer, earthexplorer.usgs.gov

26. NASA Earth Data, earthdata.nasa.gov

27. Open Topography, SRTM, opentopo.sdsc.edu/raster ?opentopoID=OTSRTM.082015.4326.1

28. QGIS 2.18.22 LTR, GNU General Public License, qgis.org/en/site

29. HEC-RAS, www.hec.usace.army.mil/software/hecras 